\title{
Winter 1999: a valuable test of the avalanche-hazard mapping procedure in Switzerland
}

\author{
Urs Gruber, Stefan Margreth \\ Swiss Federal Institute for Snow and Avalanche Research, CH-7260 Davos Dorf, Switzerland
}

\begin{abstract}
In Switzerland three large snowfall periods led to numerous large avalanche events, causing the deaths of 17 people, damage to about 1000 buildings and blockage of many important traffic systems. This situation was a valuable test of the avalanche-hazard mapping procedure developed in Switzerland since the last extreme avalanche winter in 1951. In most cases, the avalanches stopped within the avalanche-hazard zones. However, approximately 40 of about 1200 large avalanche events passed the limits of the existing hazard zones. The primary deficiency was underestimation of the hazard of powder-snow avalanches. The other reason the hazard-zone boundaries were passed was multiple avalanche events in a single track within a short time period. In addition, some fracture depths were larger than those used in avalanche-dynamics calculations. Therefore, the guideline assumptions for defining the fracture depths are questioned. Winter 1999 impressively underlined the danger of avalanches in mountainous regions. It emphasized the importance of avalanche-hazard mapping, showed the existing deficiencies and provided a large amount of field data that will help to improve our knowledge of avalanche dynamics.
\end{abstract}

\section{INTRODUCTION}

In the Swiss Alps three large snowfall periods between 27 January and 25 February 1999 led to about 1200 large avalanche events, causing the deaths of 17 people, extensive damage to more than 1000 buildings and blockage of many important traffic systems. During these 30 days the new-snow depths in large areas on the northern flank of the Alps were $>500 \mathrm{~cm}$. This corresponds to a maximum recurrence of 80-100 years. In many parts of cantons Valais and Grisons there was $>300 \mathrm{~cm}$ of new snow, corresponding to a recurrence of approximately 40 years (SLF, 2000).

This situation was a valuable test for the avalanchehazard mapping procedure developed in Switzerland since the last extreme avalanche winter in 1951 (Frutiger, 1980). The basics of avalanche-hazard mapping in Switzerland are defined in guidelines (BFF and SLF, 1984) and must be applied in all communities in mountainous regions. Four different zones, distinguished by impact force and frequency, are used to define the degree of hazard of avalanches, which is then used for land-use planning. In the area of greatest hazard (red) it is forbidden to build houses. In the zone of moderate hazard (blue), houses may be built but must be reinforced to withstand impact pressures of up to $3 \mathrm{t} \mathrm{m}^{-2}$. The yellow zone delineates areas where either avalanches occur very rarely or the influence of a powder-snow avalanche can be expected. Until now, the delineation of this yellow zone was not mandatory. The fourth zone (white) is considered to be free of avalanche hazard.

For many of the avalanche-hazard maps in Switzerland the Voellmy-Salm model has been used to calculate the runout distance and the limits between the red and blue zones (Salm and others, 1990). However, this model treats only dense-snow avalanches. Before 1999, powder-snow avalanche models were only very rarely used in practice to calculate the extent of the yellow zone. The hazard of powder-snow avalanches was only considered using information about historical powder-snow events on a specific avalanche track and the personal experience of experts.

\section{DEMONSTRATED USEFULNESS}

The usefulness of avalanche-hazard mapping in Switzerland can be evaluated by comparing the amounts of damage caused by the avalanche cycles of 1951 and 1999. On the one hand, although the intensity and the regional distribution of the avalanche activities are not exactly comparable, the hazard potential of both winters can be considered as being in the same range. On the other hand, the damage potential has increased remarkably since 1951: The number of houses $>1000 \mathrm{~m}$ a.s.l. (i.e. in the area most exposed to the risk of avalanches) has increased by a factor of 3, to a total of 126978 buildings (SLF, 2000 , p. 163). The insurance value of those buildings has increased even more, by a factor of 30 . While the number of residents in the Alpine regions of Switzerland has hardly changed, tourism has increased the number of lodging nights by a factor of 4 since 1951. Given that February is a high-season month of winter tourism, in 1999 significantly more persons were exposed to Alpine regions than in 1951 (SLF, 2000, p. 163, 169f.). Moreover road traffic increased between 1960 and 1995 by a factor of 6 , and railway traffic by a factor of 2 (SLF, 2000, p. 164).

Despite this threefold higher damage potential at more or less the same hazard potential, the number of significantly damaged or destroyed buildings was lower by a factor of 1.5 in 1999 than in 1951 (about 1000 instead of about 1500 houses damaged; SLF, 2000, p. 124, 201).

For this reduction two means of protection, "avalanchehazard mapping" and "defence structures", are mainly responsible. It is not possible to distinguish clearly between 

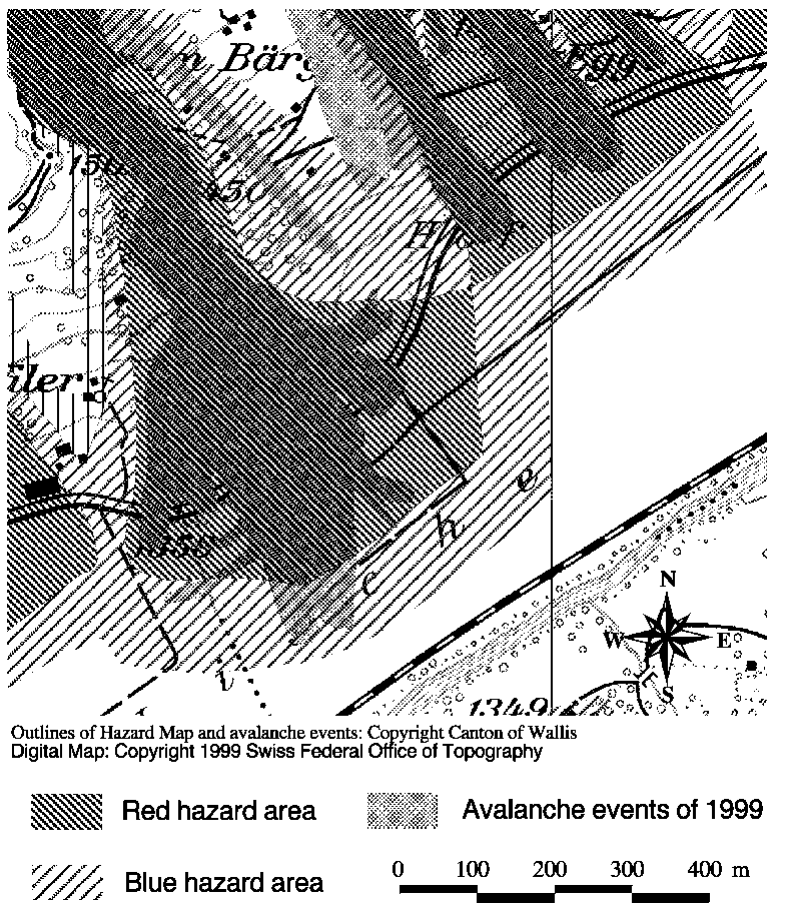

Fig. 1. Avalanche-hazard map of Ulrichen, compared to the avalanche event of 22 February.

their contributions, but the established hazard maps have successfully prevented many new houses from being built in endangered areas.

Avalanche-hazard mapping has, furthermore, contributed to the reduction of deaths in houses and on roads (1951: 97; 1999: 17), since the maps are often used in decisions to evacuate or to close traffic roads (SLF, 2000, p. 172f., 329). However, it is not possible to separate the contributions of avalanchehazard maps, defence structures, organizational means and also the luck of the individuals at risk (SLF, 2000, p. 124).

After this general judgement of the usefulness of avalanche-hazard maps for 1999 in comparison to 1951, it is necessary to look at some more specific figures with regard to the 1999 avalanches. About 40 of 1200 large avalanches crossed the outer limits of the avalanche-hazard areas and entered the white zone (SLF, 2000, p.320). All other avalanches either stopped within the avalanche-hazard zones or occurred in areas where avalanche-hazard mapping was not used (i.e. in areas with no inhabitants). Among these 40 avalanche-hazard mapping failures, only about 10 avalanches were likely single dense-snow avalanche events, as treated in the avalanche-hazard mapping procedure. Therefore, the dense-flow avalanche events stopped in most cases within the delineated limits of the red and the blue hazard zone.

The two examples of Ulrichen, cantonValais, Switzerland, and Malbun, Liechtenstein, are shown as representatives for many avalanche-hazard maps well fitted to the events of 1999. In Ulrichen a wet-snow avalanche event occurred on 22 February that was characterized by many narrowing avalanche arms in the runout zones. The deposition of this avalanche covered almost the whole red zone and stopped within the blue zone (see Fig. 1). In Malbun, on 21 and 22 February, two avalanches with an estimated frequency of $>50$ years occurred out of different release areas. The outer limits of both avalanches did not exceed the boundaries of the avalanchehazard map made in 1998 by the SLF (Margreth, 1998; see Fig. 2). In the red zone several buildings were destroyed. During the avalanche events, the whole village of Malbun was evacuated.

\section{GLEARLY IDENTIFIABLE DEFICIENCIES}

In spite of the generally well- to very well-tested usefulness of the avalanche-hazard maps, a closer analysis of the failures reveals two clearly identifiable deficiencies and some uncertainties regarding assumptions made in the avalanche-hazard mapping procedure.

\section{Powder-snow avalanches}

The most important deficiency was underestimation of the hazard caused by powder-snow avalanches. In about 25 cases the powder-snow part of the avalanche exceeded the limits of the hazard maps. Winter 1999 clearly shows that

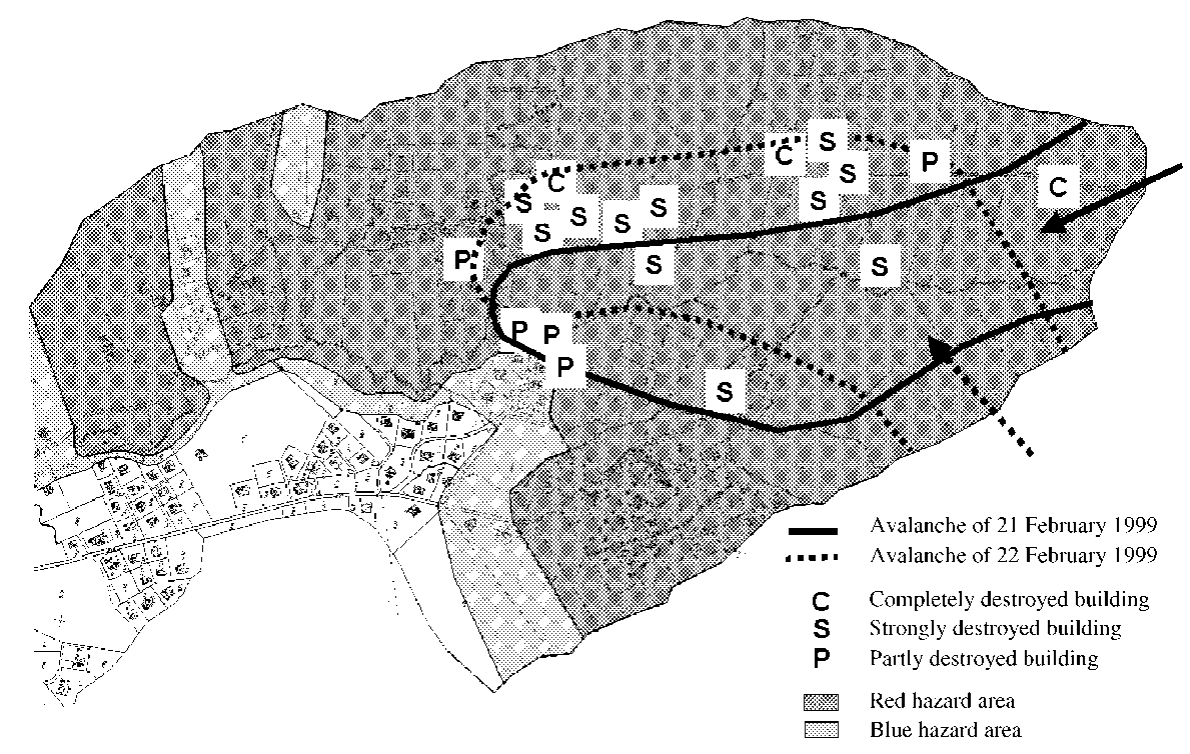

Fig. 2. Avalanche-hazard map of Malbun, compared to the two avalanche events of 21 and 22 February. 


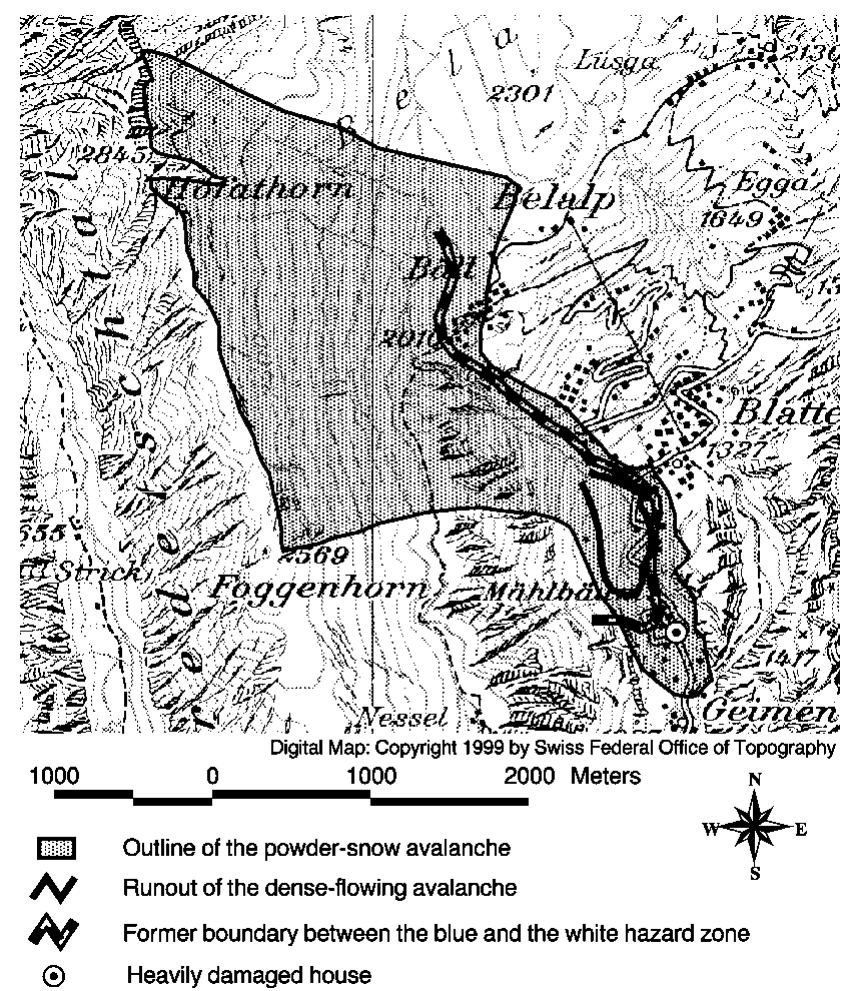

Fig. 3. Perimeter of the powder-snow avalanche in Blatten, compared with the existing avalanche-hazard map.

large powder-snow avalanches can cause substantial damage to buildings, persons and power lines.

In the past, because pressures in the runout area of powder-snow avalanches were poorly understood and since no reliable model to calculate these values was available in practice, the yellow hazard zone was often omitted or inadequately delineated in avalanche-hazard maps. In the following, two examples are given to illustrate the dimensions and the damage potential of powder-snow avalanches that occurred in February 1999.

The perimeter of the Blatten (canton Valais) powdersnow avalanche in Figure 3 shows that the release area was $3500 \mathrm{~m}$ wide. A few days later, a mountain guide visited the release area and reported fracture depths of 3-8 $\mathrm{m}$, with an average depth of about $4 \mathrm{~m}$. Whereas the dense part of the avalanche remained within the boundaries of the existing avalanche-hazard map, the powder-snow part caused damage as far as $750 \mathrm{~m}$ beyond the deposition area of the dense part of the avalanche. The house marked in Figure 3 was heavily damaged. The pressure that caused the damage had been estimated to be $>3 \mathrm{kPa}$. In the existing avalanchehazard map, a yellow zone was delineated only at the lateral limits of the avalanche but not in front of the runout zone.

In Leukerbad, canton Valais, on 25 February an avalanche that had been artificially triggered destroyed the roof of a residential house (Fig. 4), damaged neighbouring residential houses and destroyed trees. The house with the most damage was within the yellow hazard zone. However, the pressures of the powder-snow avalanche had clearly been underestimated. In addition, the runout distance of the observed avalanche exceeds the limits of the yellow hazard zone almost everywhere up to a maximum distance of $100 \mathrm{~m}$.

\section{Multiple avalanche events}

The second identifiable deficiency is the fact that about five

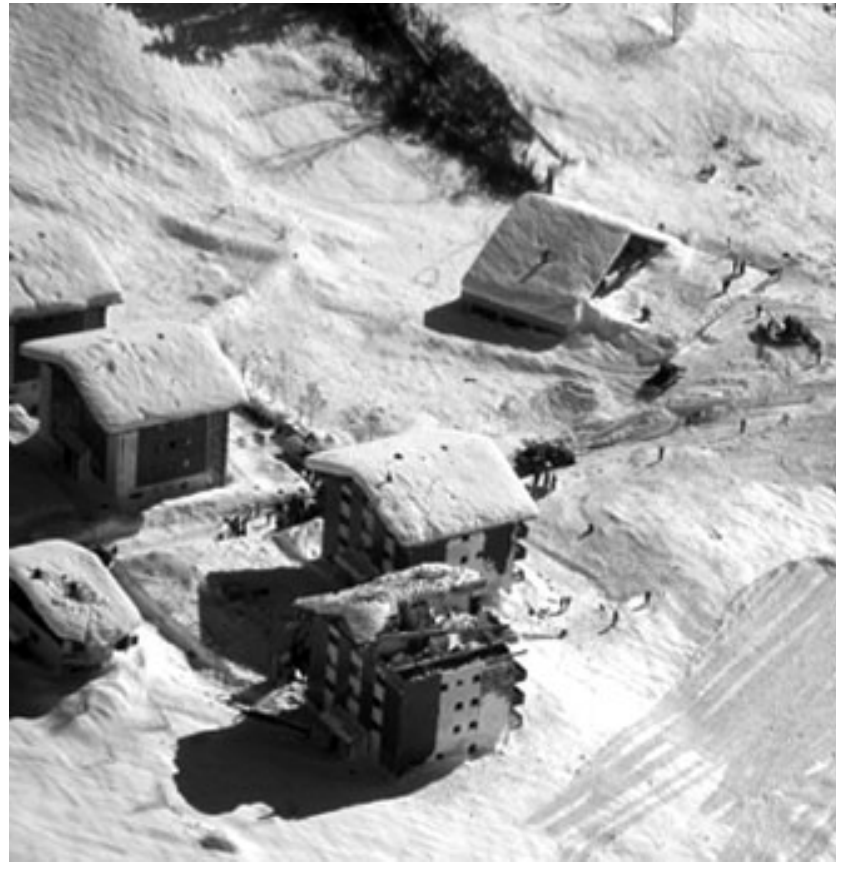

Fig. 4. Aerial picture of residential houses in Leukerbad that were damaged by a powder-snow avalanche. In the background, trees are visible that were destroyed by the avalanche.

avalanche events exceeded the limits because more than one avalanche event occurred on the same track during the avalanche cycle. Due to the deposition of the preceding events, avalanches were deflected in ways not foreseen in the hazard-mapping procedure.

In the aerial picture of the deposition area of Geschinen, canton Valais (Fig. 5), three different avalanche events can be easily distinguished. The first event (1) was a powder-snow avalanche that exceeded the limits of the blue hazard zone at the front by about $150 \mathrm{~m}$. The second event (2) was a smaller,

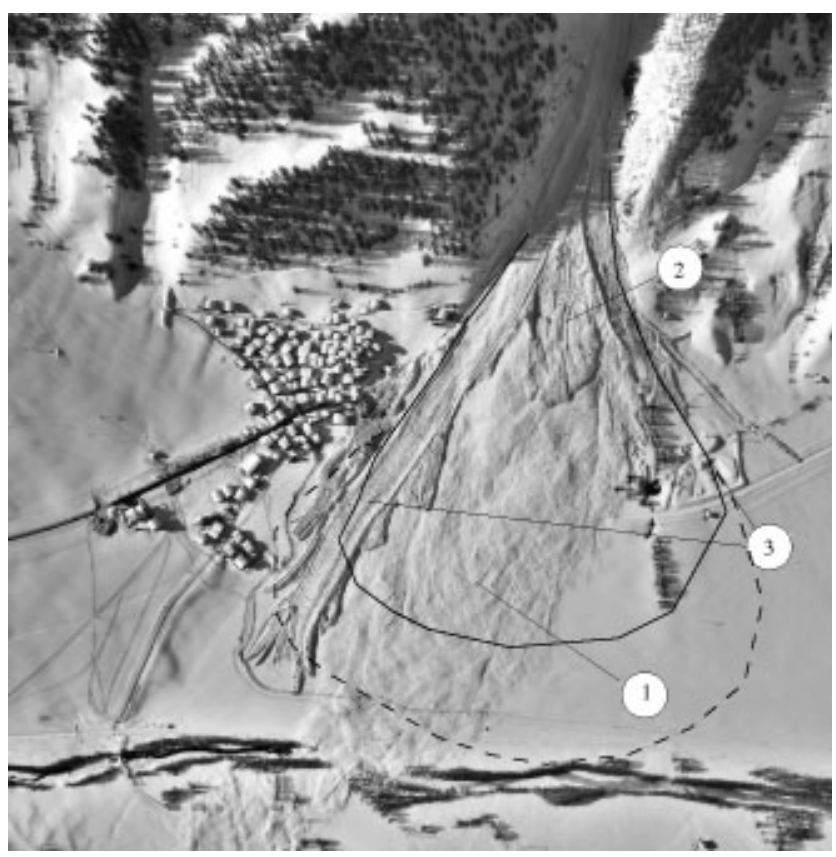

Fig. 5. Aerial picture of the deposition area of the avalanche events in Geschinen. The full line indicates the boundary of the red, the dashed line that of the blue hazard zone. No yellow hazard zone was delineated before 1999. 
wet-snow avalanche that stopped at the beginning of the open slope area. The photogrammetrically measured deposition depth of both avalanche events here was $18 \mathrm{~m}$. Due to this large deposition, the third avalanche (3) was deflected to both sides and overflowed the lateral boundary of the hazard map, destroying residential houses and killing one person.

In Lourtier, canton Valais, two avalanche events on 8 and 20 February filled the deflecting dams that protect the village. The following two avalanche events on the same track, both on 21 February, overflowed the dams.

A common attribute of all multiple avalanche events occurring on a single track and overpassing the boundaries of the avalanche-hazard maps in 1999 was a total potential release area of $>20$ ha.

\section{UNGERTAINTIES}

In addition to the clearly identifiable deficiencies, winter 1999 also reveals an important uncertainty with respect to assumptions of the fracture depth. Based on the experiences of the preceding avalanche winters of 1951, 1954, 1968, 1974 and 1984, the snow-cover increase during one single large snowfall period of 3 days $\left(\Delta H S_{3}\right)$ has been used as a standard for the basic assumption of the fracture depth. With extreme-value statistical methods this value was determined for different regions in Switzerland and different return periods. At $2000 \mathrm{~m}$ a.s.l, a maximum fracture depth $d_{0}^{*}$ of $2.1 \mathrm{~m}$ results in the most intensive snowfall regions for a return period of 300 years (Salm and others, 1990).

In 1999, the $\Delta H S_{3}$ value of most measurement stations was high but not extreme. The main characteristic of this winter was not a single large snowfall period but the sequence of three intensive snowfall periods within a time period of 30 days. In Figure 6 these periods can be very clearly recognized.

Due to the sum of all snowfall periods, many avalanches of the third snowfall period (e.g. the Blatten avalanche) had a larger fracture depth along the fracture line than the $\Delta H S_{3}$ value. Even if the fracture depth along the fracture line is generally larger than the mean fracture depth of the whole release area as used in the calculations, the assumption of a single snowfall event as a standard for calculating extreme avalanche events is strongly called into question.

However, despite the fact that many avalanches had larger fracture values than the $\Delta H S_{3}$ value, the runout distance of most dense-flow avalanches of the third snowfall period stopped within the hazard zones. This was most likely because of a warm period immediately before and at the beginning of the third snowfall period, with rainfall below $1600 \mathrm{~m}$ a.s.l., leading to higher friction in the deposition zones due to the wet-snow cover. It can be assumed that in winter 1999 the underestimation of the fracture depth was, fortunately, compensated by higher friction in the runout area.

Due to this possible compensation, it is still not clear whether a single 3 day snowfall event with low friction values, or more than one large snowfall period with higher friction values, or even three large snowfall periods with low friction values, should be used as a standard for extremeavalanche calculations. This uncertainty must be carefully analyzed with respect to the probability of meteorological situations as well as with respect to the influence of warming and/or rain leading to higher friction in the avalanche track.

In addition, a major difficulty of avalanche-hazard map-

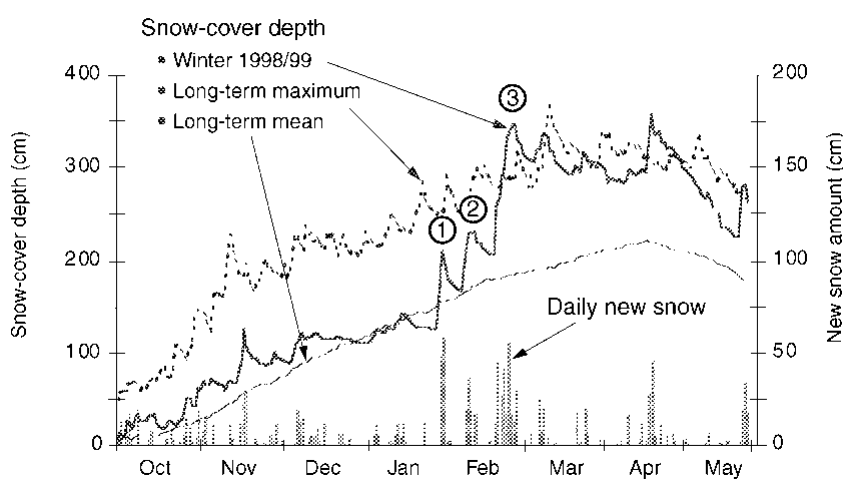

Fig. 6. Development of the snow-cover depth and the daily measured new-snow amounts at SLF's Weissfluhjoch station in 1999. For comparison, the maximum and mean values of the 62 preceding winters are given.

ping has become obvious in two of the about ten dense-snow avalanche events that exceeded the limits of the existing avalanche-hazard maps. Both avalanches occurred in Evolène, canton Valais, causing the deaths of 12 persons. The runout distances of these avalanches can be estimated by using the standard assumptions for avalanche-hazard maps in this region. Taking a look at the history of avalanche-hazard mapping in Evolène, the avalanche-hazard map of 1973 already precisely covered the outline of the northern 1999 avalanche of Evolène. However, no historical avalanche event has ever been observed in the lowest parts of both avalanche tracks. Also, an old house (built in 1678) existed in the red zone (i.e. where avalanches are expected with return periods of $\leq 300$ years). Hence, the avalanchehazard map was revised in 1992 and the hazard limits were moved upslope. Although in the revised avalanche-hazard map of 1992 the houses where people were killed were still in the blue zone, people felt safe and did not evacuate. This example clearly shows the difficulties one encounters in convincing residents of a community of the validity of an avalanche-hazard map in locations where historic records of observed avalanche events are not available.

\section{GONGLUSIONS}

Avalanche-hazard maps, together with defence structures, led in 1999 to a significant reduction in the number of houses damaged or destroyed compared to 1951, although the number of buildings in the Alpine regions has increased by a factor of three. Therefore, avalanche-hazard mapping has proved its usefulness as a long-term instrument to reduce the damage potential in Alpine regions. Furthermore, winter 1999 followed a period of 15 years with no major damage caused by avalanches in inhabited regions. The events of 1999 emphasized that it would be wrong, in periods of low avalanche activity, to reduce efforts to integrate avalanchehazard maps in land-use planning. As a direct consequence of the avalanches occurring in 1999, at least five communities in the Swiss Alps with no prior established avalanche-hazard maps have initiated avalanche-hazard mapping efforts.

Although most avalanches stopped within the boundaries of the avalanche-hazard maps, deficiencies exist for powdersnow avalanches, and multiple avalanches on a single track exist. To overcome the first deficiency, it is imperative to establish 
tools and guidelines to calculate the runout distances and the pressures of powder-snow avalanches. In November 1999, a first version of a one-dimensional powder-snow avalanche model and general guidelines for the calculations were presented to the practioners (unpublished information from M. Christen). In addition, research efforts must be focused on the development of a combined dense- and powder-snow model. To overcome the second deficiency a guideline for adequate consideration of the hazard of multiple avalanche occurrences on a single track must be developed. This guideline must treat the release-area definition of typical multiple avalanche tracks. In addition, consideration must be given to the design of deflecting and catching dams as well as to the lateral spreading in the runout area of such paths.

Uncertainties about the assumptions of the fracture depths should be carefully analyzed, and, if necessary, new rules to define the initial fracture volumes of extreme avalanche cycles must be defined. For the kind of problems that occurred in Evolène, where historic data are not available, a simple solution is not expected. Of most importance is to map, document and store all avalanche events that ever occur in places near to settlements. It may also be useful to gather examples such as Evolène to convince residents in other communities to evaluate hazard caused by rare, previously undocumented avalanche events.

Last but not least, a very positive aspect of winter 1999 is that a large amount of field data is now available that will help to improve knowledge of the dynamics of very large avalanches (SLF, 2000).

\section{REFERENCES}

Bundesamt für Forstwesen (BFF) and Eidgenössisches Institut für Schneeund Lawinenforschung (SLF). 1984. Richtlinien zur Berücksichtigung der Lawinengefahr bei raumwirksamen Tätigkeiten. Bern, Eidgenössische Drucksachen- und Materialzentrale. Bundesamt für Forstwesen; Eidgenössisches Institut für Schnee- und Lawinenforschung.

Eidgenössisches Institut für Schnee- und Lawinenforschung (SLF). 2000. Der Lawinenwinter 1999. Ereignisanalyse. Davos, Eidgenössisches Institut für Schnee- und Lawinenforschung.

Frutiger, H. 1980. Schweizerische Lawinengefahrenkarten. In Internationales Symposium Interpraevent 1980, Bad Ischl. Vol. 3. Klagenfurt, Forschungsgesellschaft für vorbeugende Hochwasserbekämpfung, 135-143.

Margreth, S. 1998. Lawinengefahrenkarte Malbun, Gemeinde Triesenberg, FL. Davos, Eidgenössisches Institut für Schnee- und Lawinenforschung. (SLF Gutachten G98.12.)

Salm, B., A. Burkard and H. Gubler. 1990. Berechnung von Fliesslawinen: eine Anleitung für Praktiker mit Beispielen. Eidg. Inst. Schnee- und Lawinenforsch. Mitt. 47. 